Article

\title{
Social education and social work in Japan: from an education welfare theory perspective
}

\author{
Yaka Matsuda \\ Assistant Professor, Faculty of Education, Kochi University, Kochi, Japan; yaka_m@kochi-u.ac.jp
}

How to Cite: Matsuda, Y. (2021). Social education and social work in Japan: from an education welfare theory perspective. International Journal of Social Pedagogy, 10(1): 12.

DOI: https://doi.org/10.14324/111.444.ijsp.2021.v10.x.012.

Submission date: 5 January 2021; Acceptance date: 1 September 2021; Publication date: 30 September 2021

\section{Peer review:}

This article has been peer-reviewed through the journal's standard double-blind peer review, where both the reviewers and authors are anonymised during review.

\section{Copyright:}

(C) 2021, Yaka Matsuda. This is an open-access article distributed under the terms of the Creative Commons Attribution Licence (CC BY) 4.0 https://creativecommons.org/licenses/by/4.0/, which permits unrestricted use, distribution and reproduction in any medium, provided the original author and source are credited • DOI: https://doi.org/10.14324/111.444.ijsp.2021.v10.x.012.

\section{Open access:}

International Journal of Social Pedagogy is a peer-reviewed open-access journal.

\begin{abstract}
This article aims to consider the position of social pedagogy in Japan in the relationship between social education and social work, by focusing on the historical development of the two. In Japan, the term social pedagogy is not as well known as it is in European countries. The term of social education is used to cover the combination of 'social' and 'education/pedagogy'. Historically, social pedagogy was influenced by Japanese social education at the beginning of the 1900s, and more recently, interest in social pedagogy is increasing, with attention from some Japanese researchers in the fields of both social education and social work/social welfare. In Japan, after the Second World War, social education and social work came to be entirely separate areas due to the establishment of social education and social welfare systems. In this article the different institutional positions of modern-day social education and social work/social welfare are first clarified. Their historical development is then explored by delving into the literature that discusses how the two first diverged. Finally, how social pedagogy is positioned in the relationship between social education and social work/social welfare is considered. This will deepen
\end{abstract}


the understanding of the issue from the viewpoint of education welfare theory as the research framework, a theory of Toshio Ogawa, one of the leading figures in Japanese social education research.

Keywords education welfare theory; social pedagogy; social education; social work; social welfare; history; Japan

\section{Introduction}

Interest in social pedagogy has increased around the world in recent years and Japan is no exception. With the establishment of the Japanese Society of Social Pedagogy in 2018, an increased number of researchers have shown interest in this field of study. One reason for their interest is that it contains both the elements of pedagogy and social work. Some Japanese researchers understand that social pedagogy is important for providing educational support to children, adolescents and adults who deal with a variety of difficulties, and for putting this support into practice. However, social pedagogy is not a new concept in Japan, since it has existed for over 100 years.

The Japanese term shakai kyoiku is a combination of social (shakai) and education/pedagogy (kyoiku) and refers to the concepts of adult education, popular education (Volksbildung) and out-of-school education. Shakai kyoiku was advocated in the Japanese language in 1877 and has since been developed by an array of theorists, taking on aspects of each historical era. One of the most influential concepts in the development of the theory was German social pedagogy (Sozialpädagogik). In 1901, Paul Natorp's Sozialpädagogik (1899) was introduced to Japan by the pedagogue Jintaro Ose, after which it was studied by his students, along with other social education researchers. At that time, there was an overlap in social work, based around social charity and social education, and efforts were being made towards greater well-being in people's lives. However, with the outbreak of the First World War, interest in social pedagogy diminished, social work waned and social education was increasingly used to indoctrinate people to go to war. After the Second World War, social education and social work came to be entirely separate areas due to the establishment of the social education and social welfare systems.

Therefore, in Japan, these entirely different areas of academia have separate institutions and separate professional training courses. In academia, social education is positioned within pedagogy, for which there is a doctoral degree. Social work/social welfare can exist independently as its own faculty (of social welfare), or can be positioned as a social welfare department in another faculty (e.g. faculties of sociology, medicine/health or hygiene). Institutionally, the laws covering these fields are the Social Education Act and social welfare law. The Ministry of Education, Culture, Sports, Science, and Technology (MEXT), which is responsible for the field of education, has jurisdiction over social education, whereas the Ministry of Health, Labour and Welfare (MHLW), which is responsible for the fields of medicine and welfare, has jurisdiction over social work/social welfare. In terms of professional titles, the former are 'social educators' (a title that has been newly applied from 2020 when, previously, only the title of 'director of social education' existed) and the latter 'certified social workers', which is a national qualification. The contents of the respective training courses also differ entirely.

In recent years, however, researchers in both social education and social work/social welfare have become interested in social pedagogy. The social pedagogy research team, with which the author is involved, is composed primarily of researchers who specialise in social education. However, members of the Japanese Society of Social Pedagogy are researchers in the area of social work/social welfare who specialise primarily in child care. Although approaching social pedagogy from different angles, the two fields appear to be converging. In summary, the relationship between social education and social work/social welfare is undergoing profound change, and the increased interest in social pedagogy is causing the two areas to meet. Why is such a phenomenon occurring?

In order to investigate this question more deeply, this article focuses on the historical development of social education and social welfare in Japan and aims to consider the relationship between the two and the position of social pedagogy within that relationship. After clarifying the different institutional positions of modern-day social education and social work/social welfare, their historical development is explored by delving into the literature that discusses how the two first diverged. Finally, how social pedagogy is positioned in the relationship between social education and social work/social welfare is 
considered. This will serve to deepen the understanding of the issue from the viewpoint of education welfare theory, a theory of Toshio Ogawa, one of the leading figures in Japanese social education research.

Education welfare theory is a concept that attempts to connect education and social welfare. Toshio Ogawa (1985), who advocated this theory in the 1970s, reinterpreted Germany's Sozialpädagogik, which translates literally as 'education welfare theory' (p. 155). In Japan, social pedagogy is often understood as a concept in which pedagogy and social welfare overlap. The author also has an interest in social pedagogy and researched on social pedagogy in Sweden (Socialpedagogik) from a pedagogical perspective. Although social pedagogy is interpreted in diverse ways in Sweden, this article approaches social pedagogy from a Japanese perspective.

In this article, education welfare theory is used as a theoretical framework to achieve the above-mentioned goals. Ogawa's definition of education welfare theory is that it 'underlies the social welfare of today, and particularly child welfare services. Conceptually, it aims to systematise the learning and educational rights for children, adolescents, and adults who are deprived or suffering from neglect' by society (Ogawa and Takahashi, 2001, p. 2). Specifically, the problems of pre-schoolers, long-term absent students, poor children and those suffering from discrimination, juvenile delinquency, junior high night-school attendees, children in institutions (e.g. orphaned, neglected, abused or emotionally disturbed children), children in residential facilities and children dependent on school meals were all described as problems that constitute a 'valley' between education and welfare in Japan during the high economic growth period of the 1970s (Ogawa and Takahashi, 2001, p. 5). For Ogawa and Takahashi (2001), education is 'the act of consciously arranging the human form into what it ought to be' and welfare is 'the act of creating the social conditions that provide a foundation for living a healthy cultural life' (p. 19). However, the human form largely depends on the influences of the social environment into which the human is placed; in other words, what kind of social life the person is living. Also, when considering the educational activities necessary for a person to live a healthy cultural life, education and social welfare are complementary with one another and are essentially inseparable. However, Ogawa and Takahashi (2001) point to a problem that arises due to the institutional division in the valley between the two administrations, where neither exhibits their original function and children fall outside of both welfare and education. What are regarded by Ogawa and Takahashi (2001) as social issues seem to overlap with social pedagogical issues that appear in the history of Western nations.

Before moving to the next section, the terms used in this article are defined. As previously mentioned, social pedagogy and social education are considered separate in Japan. Therefore, in the context of Japan, social education is used as a term to connect society and education/pedagogy. The term social pedagogy, in contrast, refers specifically to the social pedagogy that has taken root in Europe, and social work (shakai jigyo) and social welfare (shakai fukushi) are often considered separately in Japan. For the purposes of this article, social work (shakai jigyo) is an area that overlapped with social education, which existed in the system prior to the Second World War, whereas social welfare (shakai fukushi) is based on the post-war system in which it is considered separate from social education. Note that the use of these definitions is for the convenience of this article, and in reality, it is generally understood that social work and social welfare are interchangeable. Table 1 summarises these findings.

Table 1. Terminology used in this article.

\begin{tabular}{|c|c|c|}
\hline Terminology & Japanese & Meaning \\
\hline Social pedagogy & $\begin{array}{l}\text { Shakaiteki kyoiku gaku } \\
\text { (literal translation) }\end{array}$ & A term that has taken root historically in Europe. \\
\hline Social education & Shakai kyoiku & $\begin{array}{l}\text { A term that originated in Japan and connected } \\
\text { social (shakai) and education/pedagogy } \\
\text { (kyoiku/kyoiku gaku). }\end{array}$ \\
\hline & & $\begin{array}{l}\text { A term used prior to the Second World War. } \\
\text { Related to social education. Currently rarely used. }\end{array}$ \\
\hline Social welfare & Shakai fukushi & $\begin{array}{l}\text { A term used post-war. Systematically, no relation } \\
\text { with social education. }\end{array}$ \\
\hline
\end{tabular}




\section{The position of social education in law}

Social education in Japan is regulated by law, facilities are set up and operated accordingly, as are the staff who are positioned within it. Broadly defined, social education includes not only projects carried out by the social education administration, but also the activities of non-profit organisations and other community activities as nonformal/informal learning. In this article, however, in order to clarify its differences from social welfare, the legal systems of both will first be described. The definition of the Social Education Act, as stipulated by the Social Education Division, Lifelong Learning Policy Bureau, Ministry of Education, Culture, Sports, Science and Technology (MEXT) is outlined in Box 1 below.

\section{Box 1. Social Education Act of 1949 (Source: MEXT, 2020a).}

Chapter 1: General Rules

(Definition of Social Education)

Article 2: Under this law, 'social education' is based on the School Education Act (Act No. 26, 1947), and, excluding educational activities conducted as part of a school curriculum, refers to organised education activities prominently conducted for children, adolescents and adults (including physical education and recreation activities).

As made evident by the law, everything outside the school curriculum falls under social education. However, the educational content of each local government is diverse because the prioritised content differs depending upon the issues faced by the region. For example, local governments where ageing is a major regional issue will focus on health and cultural activities for older people, whereas areas which are high in foreign migration will concentrate on projects that aim to promote multicultural coexistence. The following are administrative duties stipulated by the Social Education Act, some of the specific content of which is focused on and summarised in Box 2.

In Japan, education provided to children by their parents is generally referred to as home education. Although social education administration does not intervene to support families, many are sustained by local child-rearing circles held at social education facilities. Social education facilities are attended by children on Saturdays, Sundays and after school where, among other things, they learn social etiquette by spending time with local adults and other children. This can help with their home education. The law states that social education falls between school education and home education (although it is sometimes considered part of home education). As demonstrated by the assigned work content of each local government, social education administration has a wide scope. The directors of social education are assigned as professionals who are responsible for these businesses. MEXT explains the role of directors of social education in Box 3.

Box 2. Duties of national and local governments for social education, shown in an excerpt from the Social Education Act of 1949 (Source: MEXT, 2020a).

Article 3

1 The national and local governments must, in compliance with this law and other laws and regulations, strive to foster an environment in which all citizens can take advantage of opportunities and locations so as to enhance their own cultural education in accordance with their real lives, by setting up and operating facilities necessary for encouraging social education, holding meetings, preparing materials, distributing materials and other such methods. 


\section{Box 2. Cont.}

2 In carrying out the duties set forth in the preceding paragraph, national and local governments shall endeavour to secure cooperation with school education and home education in view of the fact that social education is closely related to both, and simultaneously give necessary consideration to contribute to the improvement of home education.

Article 5: The Board of Education of the municipality shall carry out the following affairs regarding social education, within the allocated budget for the relevant region.

1. Providing necessary assistance for social education.

2. Appointing members to a social education committee.

3. Installation and management of a Kominkan (community learning centre).

4. Installation and management of libraries, museums, youth centres and other social education facilities.

5. Establishment and encouragement of courses for social education conducted by schools.

6. Establishment of lectures and holding/encouraging discussions, seminars, lectures, exhibitions and other meetings.

7. Guarantee and encourage learning opportunities related to home education.

8. Hold and encourage meetings for vocational education, and science and technology guidance related to industry.

9. Hold and encourage meetings to teach how science can improve daily life.

10. Hold and encourage athletic meets, competitions and other meetings for guidance in physical education.

11. Hold and encourage presentations of music, theatre, fine art and other arts.

12. Implement and encourage projects that provide children and adolescents with opportunities for social service activities, such as volunteer activities, nature experiences and other experience-based activities.

13. Publish and distribute social education materials to the general public.

14. Provide facilities, equipment and materials necessary for audiovisual education, physical education and recreation.

15. Information exchange and research.

16. Other affairs necessary to accomplish the duties set forth in Article 3, Paragraph 1.

\section{Box 3. Role of directors of social education (Shakai kyoiku shuji) (Source: MEXT, 2020a).}

The Director of Social Education is a professional staff member assigned to the secretariat of the Board of Education of Prefectures and Municipalities, who plays a role in providing professional and technical advice and guidance to those who provide social education aided by the Assistant Director of Social Education. Their duties are diverse and include planning and implementing social education projects sponsored by the Board of Education, providing guidance and advice for projects sponsored by social education facilities in the jurisdiction as well as on the activities of social education related organizations, and planning and implementing training programmes for social education administrative staff in the jurisdiction.

Until April 2020, it was necessary to have obtained the designated credits for social education at university in order to assume a role in the social education profession and be verified as a director of social education by the Board of Education of local government. However, because the system does not make extensive use of social education expertise, anyone who has earned a given number of credits can now call themselves a 'social educator' (Shakai kyoiku shi). As this is a new system, there is limited feedback regarding the placement and utilisation of social educators, but there is the expectation that they would be proficient in a wide range of fields and settings, such as schools, social welfare administration and non-profit organisations, as social pedagogues are in Germany and the Nordic countries. 


\section{The legal status of social welfare}

In this section the Social Welfare Act, established by the MHLW, is described. First, the definition of social welfare will be examined, after which the definitions for each of the services summarised and introduced (see Box 4).

\section{Box 4. Social Welfare Act of 1951 (Source: MHLW, 2020a, 2020b).}

Chapter 1: General Rules

(Definitions)

Article 2: The term 'social welfare services' as used in this Act means both Type 1 and Type 2 social welfare services.

The following are classified as Type 1 social welfare services:

1. Services related to livelihood protection.

2. Services related to child welfare.

3. Services related to welfare for older people.

4. Services related to comprehensive support for the daily and social lives of persons with disabilities.

5. Deleted (*Services related to the welfare of persons with intellectual disabilities was previously defined, but this was revised in 2000 due to the promotion of community-based welfare).

6. Services related to the prevention of prostitution.

7. Services that manage vocational workshops and lend funds to those who experience difficulty earning a living.

The following are classified as Type 2 social welfare enterprises:

1. Living support / consultation services for those who have difficulty earning a living. 1-2. Employment training services for people in need.

2. Child-rearing / nursing support services. 2-2. Childcare services. 2-3. Adoption support services.

3. Mother-child / father-child family support services.

4. Services to care for older people. 4-2. Disability welfare service / consultation services.

5. Welfare services for the physically handicapped.

6. Consultation services for those with intellectual disabilities.

7. Deleted.

8. Residential use mediation services for those with difficulty earning a living

9. Services that provide free or low-cost medical care for those with difficulty earning a living.

10. Free or low-cost mediation services for long-term care facilities or long-term care clinics for those with difficulty earning a living.

11. Settlement work.

12. Welfare service use support services (mainly for those with mental disorders).

13. Services that contact or subsidise the services of each of the previous tasks or tasks in the previous paragraph.

The social welfare services described above will have a lot in common with the social work/social welfare of other countries. However, in Japan, directors of social education are rarely involved in these projects. Similarly, certified social workers are not involved in the administration of services that are classified under the Social Education Act. Legally, these are completely separate and, therefore, the professions have different requirements. The laws governing certified social workers are reviewed in Box 5.

Certified social workers require a national qualification, and therefore must take the national examination after obtaining the designated credits at university. Only after passing the exam are they able to take on the title of certified social worker and work as a professional in charge of the above-mentioned services, regardless of whether they operate in the public or private sector. The qualifications of the three professions are shown in Table 2. 
Box 5. Definition of certified social worker excerpted from the Social Welfare Act of 1951 (Rev. 1987) (Source: MHLW, 2020b).

Certified Social Worker and Certified Care Worker Act

Article 2: The term 'certified social worker' as used in this Act means a person with expert knowledge and skills who provides advice, guidance, welfare services in consultations about the welfare of persons with physical disabilities or mental disorders and intellectual disabilities or persons facing difficulty in leading a normal life due to environmental factors, and a person engaged in the business of communicating and coordinating with and providing other assistance to doctors, other health and medical service providers, and other related parties.

Under the current legal system, these professions are divided systematically, and so social education and social welfare are kept entirely separate. However, historically, former social education included areas that closely resemble current social welfare, and there was a time when the distinction between social education and social work was not so clear.

Table 2. The qualifications of professions.

\begin{tabular}{|c|c|}
\hline Title & Qualification \\
\hline Director of Social Education & $\begin{array}{l}\text { Have completed the required university credits for social education; } \\
\text { have been nominated by the municipality. }\end{array}$ \\
\hline Social Educator & Have completed the required university credits for social education. \\
\hline Certified Social Worker & $\begin{array}{l}\text { Have completed the required university credits for social welfare; } \\
\text { have passed the national examination. }\end{array}$ \\
\hline
\end{tabular}

\section{The historical development of social education}

As previously mentioned, the term social education in Japan originated in 1877. The term was first used by Yukichi Fukuzawa, a philosopher and educator, in one of his lectures. Fukuzawa's portrait is on the current $¥ 10,000$ note, and he is well known throughout Japan. His thoughts and remarks had a great influence on society at the time. He anticipated that young people would play a leading role in the modernising society of Japan, preached the need for the young to continue self-education after leaving school and advocated for social education as a type of 'education in society' as opposed to the education received in school. One could say that the idea of lifelong learning had already been conceived in Japan at that time. Fukuzawa only used the term 'social education' in his lectures, but one of his students, Jiro Yamana (who theorised social education with him), wrote the book Social Education Theory (1892), which was the first written account of the theories of social education in Japan (Matsuda, 2007, p. 7).

Subsequently, pedagogues interested in the connection between society (shakai) and education (kyoiku) sought to refine the theory of social education. German philosophers and pedagogues were central to this development. For example, Otto Wilman, Fredrich Daniel Ernst Schleiermacher, Paul Bergemann and Paul Natorp garnered attention from the end of the 1890s until the early 1900s. The Japanese translations of Sozialpädagogik (by Natorp in 1899) and Sozialpädagogik (by Bergemann in 1900) were published between 1901 and 1902 (Matsuda, 2007, p. 18). In these works are matters pertaining to education, such as education for children with disabilities and child protection or adult education, which had been lacking in social education at the time. With the establishment of social education, and through its comparison with social pedagogy, contemporary researchers discovered an overlap between social pedagogy, social education and social work (Matsuda, 2007, pp. 38-9). Taking as Fukuzawa's starting point 'social education as self-education', social education expanded to comprise concepts that included the socially vulnerable, while maintaining adult education as one of its pillars. In such a fashion, the concept of Japanese social education went on to develop by incorporating 
predominantly German ideas on social pedagogy. Incidentally, it was not until in the 1970s that Japan took notice of Herman Nohl's theories that were introduced for example in the Nordic countries.

With the theorisation of social education and the expansion of social education practices in 1919 after the First World War, the Ministry of Education established the 'Ordinary Academic Affairs Bureau Section 4' (hereinafter referred to as 'Section 4'), which was responsible for the administration of social education. Section 4 was responsible for the management and implementation of adult education, libraries, museums, special education and youth work. In 1924, Section 4 was renamed the 'Social Education Division'. The entertainment industry was added to the list of matters under their jurisdiction, and public social education services were expanded (Matsuda, 2013, pp. 29-30). Around the same time, in 1920, the 'Social Bureau' was established in the Ministry of the Interior, which was placed in charge of relief services.

The Social Education Division was established under the Ministry of Education, but it was the Social Divisions or Education Divisions in local prefectural governments that became responsible for carrying out Section 4 work. With the administration of social education under local government, the directors of social education were progressively placed in charge of services. However, the placement of these directors varied from region to region; some were assigned to the Social Division and some to the Education Division. Even though the arrangements differed, the tasks for which they were responsible were similar (Matsuda, 2004, pp. 167-8). As will be described later, with the establishment of the Social Affairs Bureau in the Ministry of Home Affairs, the creation of social departments progressed even in rural areas, and in some areas social workers were assigned to these social departments. At the time, it is probable that the directors of social education and social workers were in charge of almost the same work, and only the placement and title differed depending on the area.

By the 1920s, the theories of social education had evolved on the basis of equal education opportunities and democracy. However, in the 1930s, Japan entered a nationalistic emperor system. All educational activities, not just those related to social education, came to be used to indoctrinate people and send them to war. As far as social education was concerned, the Social Education Division was changed to the Social Education Bureau and transformed into an administrative agency to train the youth and control the minds of adults through propaganda and indoctrination. The former democratically elected Chief of the Social Education Division of the Ministry of Education was removed at an early stage (Matsuda, 2007, pp. 33-5). The nationalist system persisted until the end of the Second World War.

Social education played a major role in rebuilding desolated areas after the Second World War. After reassessing the nationalistic wartime ideas, the Social Education Act was enacted in 1949 grounded in democratic ideals. Based on this law, the government has promoted the establishment of Kominkan nationwide, which serve as regional bases with various functions, such as promoting the region, supporting local industry and community welfare. Based on the ideas derived from social education, residents gathered together, shared wisdom and had discussions about how to rebuild the local society. The enactment of the Social Education Act was significant as it made it possible for services to expand across the entire country. Conversely, the social education administration that was put into place under the Social Education Act was positioned entirely under educational administration. Considering that in the 1920s it was often positioned between the Social Division and the Educational Division, one could say that the administration of social education dealt with a wider range of works related to social work before, rather than after, the war. While post-war legislation was important, due to its limited definitions, the focus was undeniably overly attentive to educational activities and did not include social work. It is patently clear that this system served to highlight the divisions among the administrations.

Since 2000, however, the importance of cooperation between educational administration and social welfare administration has been recognised by researchers, administrative organisations and practitioners, leading to a growing interest in collaboration between education and social welfare. The background of this movement includes the social contexts, such as the rising employment rate among women (Shirahase, 2006) and continuing educational disparities (Hirasawa, Yoshida and Fujiwara, 2013). Neoliberalism has led to the establishment of systems aimed at solving problems that cannot be solved by the family, educational or social welfare sectors alone. Improvements have been made, such as assigning social workers to schools (from 2008), and institutions like the Children's Comprehensive After School Plan (2014) which is a collaboration of the MEXT (education administration) and the MHLW (social welfare administration) to create a place for children after school. In the area of social education, lifelong learning projects were expanded to encourage the social participation of older people in each region. As a theory that deals with these efforts and practices, researcher interest in social pedagogy has once again 
increased and several researchers, including the author, aim to build new theories of social education for Japan by following the trends of social pedagogy research in Germany, the Nordic countries, the United Kingdom and the United States. Interest in social pedagogy research is also increasing in the area of social welfare. Thus, it could be said that social pedagogy has instigated a confluence between social education and social welfare.

\section{From social work to social welfare: a historical perspective}

This section examines how current social welfare (shakai fukushi) developed from the era of social work (shakai jigyo). In Japan, the history of social work can be traced back to ancient times. A relief system was in place that encouraged relatives and local residents to provide mutual aid to one another when natural disasters, a bad harvest or plagues caused distress to people's lives. This study focuses on the early 1900s when social work, which formed the basis of current social welfare, was institutionalised, and traces the process that led to the current rendition of social welfare.

The Military Relief Act of 1917 established the Relief Division of the Ministry of the Interior, which evolved into the Social Affairs Division in 1919; however, social work administration, the basis of social welfare, began officially in 1920 with the Social Affairs Bureau (Kikuchi, Shimizu, Tanaka, Nagaoka and Murota, 2003, p. 84). The main duties of the Social Affairs Bureau were matters related to (1) food assistance and relief, (2) military relief, (3) the relief and prevention of unemployment and (4) child protection (Endo, 1991, p. 117). According to survey materials from the Ministry of Interior at the time, these kinds of social work-related facilities and services, such as free midwifery, childcare, child counselling, housing supply, accommodation protection, public markets, basic food canteens, public bathhouses, employment placements, out-of-hospital emergency medical care, free medical care (medical expenses), cultural assimilation projects, settlement work and so on, were carried out by both the public and private sectors (Kikuchi et al., 2003, p. 89). At the time, social work policies had already been established in the UK and other European capitalist countries, and social work was already underway in the United States. The establishment of social work in Japan developed in tandem with each of these countries (Kikuchi et al., 2003, p. 83).

One aspect behind the institutionalisation of social work in Japan was the unification of the administrative structure. After the First World War, as social problems became more serious and the labour movement intensified, it was necessary to unify the administrative structures for social administration and labour administration, which had previously been dispersed among government agencies (Endo, 1991, p. 117). Democracy was tolerated to a certain extent, and policy responses to social and living problems were deemed necessary to maintain social cohesion. Thus, social policy and social work emerged under the slogans of 'social solidarity', 'social improvement' and 'labour cooperation'. However, this was accompanied by severe crackdowns on social movements (Kikuchi et al., 2003, p. 82). The Social Affairs Bureau was tasked with formulating and implementing social policy measures and assuming a controlling function for social movements in collaboration with local police agencies. The goal was to control the nation and foster loyalty and patriotism by providing people with the benefits of state social work. In summary, on the surface, it appeared that Japan's social services at the time was intended to save lives, but in reality it was one of national control.

At the time, social service managers were assigned to prefectural local governments to lead social work. In 1925, the local social work staff system was enacted, and there was progress in the placement of social work managers and assistant social work managers who were engaged in social work administration (Hatanaka, 2011, p. 45). The education for social workers was undertaken by several public and private organisations from the late 1920s. Social work faculties and departments were set up at several universities to provide social work education, but they were abolished and reorganised during the war again China in the 1930s (Kikuchi et al., 2003, p. 122).

In the 1930s, the wartime regime became stronger and, due to the dramatic increase in military spending in the national budget, spending in other areas of the budget was drastically reduced. As a result of the enactment of the National Mobilisation Law, the mobilisation of supplies and labour fell under the authority of government during the war, and every aspect of people's lives was controlled. The changes in political and social conditions had a great impact on social work. For example, social work was renamed 'welfare services' (Endo, 1991, p. 157). Furthermore, spending on relief services and child protection, which had previously been carried out as social services, was reduced, while military spending 
and the promotion of physical fitness became the central services of government (Kikuchi et al., 2003, pp. 130-1). This system continued until the end of the Second World War, during which time social work hardly functioned. Japanese social work certainly lacked 'citizenship' and 'modernity' before the war (Yoshida, 1966, p. 94).

During the post-war occupation, Japan began examining its non-military and democratic social work and revising the feudal social work system. Academics, administrators and citizens alike discussed the meaning and importance of peace, freedom, tradition, modernisation and the emperor system. Advocates introduced the social work philosophies of the United States and other Western countries, influencing the democratisation of social work in post-war Japan (Yoshida, 1966). Several Japanese researchers have included social security under the umbrella of 'social welfare', however, this meant dispelling the image of militaristic social work (Okamura, Shimada, Yokoyama and Yoshida, 1980). In 1951, the Social Welfare Act was enacted. In this law, the policy of democratic operation of social work projects and logical operation by the public sector were clearly defined (Yoshida, 1966). Thus, social work developed after the Second World War to promote democratic society by changing the term to social welfare.

\section{Conclusion}

The institutional position of social education and social welfare and the differences in their historical development has been explored. Institutionally, social education is positioned under educational administration and social welfare under welfare administration and, while the two may cooperate, they cannot merge. However, historically, there was a time when social work and social education overlapped (1910s-20s). At that time, the jurisdictions, systems and professions of the two areas differed, but records show conflicts between the services because both administrations were carrying out similar projects (Ogawa, 1962, p. 49). Over time, following the Second World War, the respective systems were put in place and both areas developed separately. However, after 2000, social welfare and social education officials began to seek cooperation and integration with one another, based on the ideas of education welfare theory. Some researchers are now paying attention to social pedagogy in order to develop education welfare theory as a theoretical or philosophical base.

When social pedagogy was first introduced to Japan, there were many who found something in it that had been lacking in Japanese social education up until that point and they started to observe it closely. Based on its ideas, social education researchers developed theories to include socially vulnerable people. What were the historical and social characteristics of social pedagogy in Japan?

One consideration was its relationship with the welfare state system. When social pedagogy was first noticed in the early 1900s, Japan was in a period of rapid modernisation. During that time, social education officials promoted democracy-based social inclusion to help people lead better lives. However, the war led to a loss of almost everything that had been accomplished. After the Second World War, Japan underwent a period of high economic growth, and neither the areas of social education nor social welfare received much attention from social pedagogy. Since 2000 Japan, like many other countries, has undergone accelerating neoliberalism, which has once again brought social pedagogy into the spotlight. In an era when the country is financially wealthy, a large number of citizens can rely on social welfare services to live a stable life. However, fluctuations in the financial base can make it difficult for more vulnerable citizens in a number of ways. At such times, it may be necessary to provide enhanced services to discover the potential of these people, and to assist them to regain their own lives through educational support. The author does not agree with the idea that the state should forego its responsibility to its people and prefers to believe that individuals are not simply recipients of government services; every citizen can become an active member of society and play their part in building a positive society where people's well-being is key. At present, some Japanese researchers have high expectations for social pedagogy, and believe it could be an important theory to support the creation of such a society.

On that occasion, the role of social educators could be expected. Social educators could improve the support available to address the social issues which are provided by administrative sections, non-profit organisations and private organisations that have not previously involved directors of social education and certified social workers. However, since the role of social educator is a new one, challenges remain, such as developing curriculum content and the lack of widespread recognition in society. Above all, there is an insufficient theoretical foundation for enhancing collaboration among 
social education, social work and the other related fields. There is an urgent need to reconsider the concept of social education - widening it to include social pedagogical ideas - and elucidate the significance and issues of social pedagogical practices in Western countries in the Japanese context.

\section{Funding}

This work was supported by JSPS KAKENHI Grant Number 20K13874.

\section{Declarations and conflict of interests}

The author declares no conflicts of interest with this work.

\section{References}

Endo, K. (1991). The development of social welfare. Tokyo: Fumaido Publishing.

Hatanaka, A. (2011). The formation of social work administrative organizations. In N. Shimizu \& P. Kwangjoon (Eds.), The history of social welfare. Kyoto: Minerva Publishing, 44-5.

Hirasawa, K., Yoshida, K., \& Fujiwara, S. (2013). Trends and issues in studies on social stratification and education. The Journal of Educational Sociology, 93, 151-91.

Kikuchi, M., Shimizu, N., Tanaka, K., Nagaoka, M., \& Murota, Y. (2003). The history of Japanese social welfare. Kyoto: Minerva Publishing.

Matsuda, T. (2004). The establishment of modern Japanese social education. Fukuoka: Kyushu University Press.

Matsuda, T. (2007). The establishment of modern Japanese social education. Fukuoka: Kyushu University Press.

Matsuda, T. (2013). Social education in Japan before WWII. In B. Kobayashi, O. Ito \& J. Lee (Eds.), Social education and lifelong learning in Japan: For the new era. Okayama: University Education Press.

Ministry of Education, Culture, Sports, Science and Technology (MEXT). (2020a). Social Education Act of 1951 (Law No. 227 of 10 June Showa 24). Accessed 13 September 2021. https://www.mext.go.jp/a_ menu/shougai/houshi/hourei/03081202.htm.

Ministry of Education, Culture, Sports, Science and Technology (MEXT). (2020b). Directors of social education and assistant directors of social education. Accessed 13 September 2021. https://www. mext.go.jp/a_menu/shougai/gakugei/syuji/index.htm.

Ministry of Health, Labour and Welfare (MHLW). (2020a). Social Welfare Act. Accessed 13 September 2021. https://www.mhlw.go.jp/web/t_doc?datald=82001000dataType=0pageNo=1.

Ministry of Health, Labour and Welfare (MHLW). (2020b). Certified Social Worker and Certified Care Worker Act. Accessed 13 September 2021. https://www.mhlw.go.jp/web/t_doc?datald= 82021000dataType $=0$.

Ogawa, T. (1962). A genealogy of the views of social education in Japanese social work theory: A consideration of its position. Problems of Social Work, 10, 48-76.

Ogawa, T. (1985). Basic problems in education welfare. Tokyo: Keiso Publishing.

Ogawa, T., \& Takahashi, M. (2001). An introduction to education welfare theory. Tokyo: Koseikan.

Okamura, S., Shimada, K., Yokoyama, S., \& Yoshida, H. (1980). History of the Japanese Society of Social Welfare: Focusing on the early days. Japanese Journal of Social Welfare, 21(2), 63-104.

Shirahase, S. (2006). Inequality in a changing society: Hidden disparities behind the demographic shift in Japan. Tokyo: University of Tokyo Press.

Yoshida, K. (1966). Some problems in the post-war history of social work thoughts. Japanese Journal of Social Welfare, 6, 88-104. 